УДК: 314.5

$10.17213 / 2075-2067-2021-3-18-25$

\title{
РЕАЛИЗАЦИЯ ПРОГРАММ ГОСУДАРСТВЕННОЙ ПОДДЕРЖКИ РОССИЙСКИХ МОЛОДЫХ СЕМЕЙ (НА ПРИМЕРЕ РОСТОВСКОЙ ОБЛАСТИ)
}

\author{
() 2021 г. Я. В. Артамонова*, И. В. Липчанская ${ }^{* *}$ \\ "Южнный федеральный университет, г. Ростов-на-Дону, Россия \\ ${ }^{* *}$ Ростовский государственный экономический университет (РИНХ), \\ 2. Ростов-на-Дону, Россия
}

Цель исследования состоит в рассмотрении программ государственной поддержки молодых семей, реализуемых на территории Ростовской области.

Методологическая база исследования: нормативно-правовые документы Российской Федерации и Ростовской области, связанные с реализаџией семейной и демографической политики.

Результаты исследования. На основе проанализированных данных авторы работы выделили основные направления семейной политики в области поддержки молодой семьи: повышение ценности семьи, экономическая поддержка семей, помощь в улучшении жилищных условий, поддержка репродуктивной функции семьи. Выделенные направления семейной политики реализуются при помощи государственных программ поддержки молодой семьи. Опьт Ростовской области по реализаџии государственных программ поддержки свидетельствует о том, что программы поддержки молодых семей реализуются и пользуются популярностью среди молодых супругов региона.

Перспективу исследования составляет дальнейший соичологический анализ государственной семейной политики в России, а также выявление новых механизмов помощи и поддержки российских молодых семей.

Ключевые слова: семья; молодежь; молодая семья; государственная политика; семейная политика; государственнье программы поддержки; Ростовская область.

\section{IMPLEMENTATION OF STATE SUPPORT PROGRAMS FOR RUSSIAN YOUNG FAMILIES (ON THE EXAMPLE OF THE ROSTOV REGION)}

\author{
(C) 2021 Ya. V. Artamonova*, I. V. Lipchanskaya** \\ "Southern Federal University, Rostov-on-Don, Russia \\ ${ }^{* *}$ Rostov State University of Economics (RSUE), Rostov-on-Don, Russia
}

The purpose of the study is to examine the programs of state support for young families, implemented in the territory of the Rostov region.

The methodological basis of the study was formed by the regulatory legal documents of the Russian Federation and the Rostov region related to the implementation of family and demographic policy.

Research results. On the basis of the analyzed data, the authors of the work identified the main directions of family policy in the field of supporting a young family: increasing the value of the 
family, economic support for families, assistance in improving housing conditions, and supporting the reproductive function of the family. The selected areas are implemented within the framework of state programs to support young families, which are implemented by the Government of the Rostov Region, the Ministry of Labor and Social Protection of the Rostov Region, public organizations, centers of social services for the population, and non-profit organizations. The experience of the Rostov region in the implementation of state support programs shows that support programs for young families are being implemented and are popular among young spouses.

The prospect of the research is a further sociological analysis of the state family policy in Russia, as well as the identification of new mechanisms of assistance and support for Russian young families.

Key words: family; youth; young family; state policy; family policy; state support programs; Rostov region.

Введение. В настоящее время мы становимся свидетелями трансформационных процессов в институциональном пространстве молодой семьи, которые требуют глубокой социологической рефлексии.

Меняются функции и образ жизни молодой семьи $[1,2]$, претерпевают изменения ценностные ориентации и установки молодых супругов, что вызывает появление различных моделей семейно-брачных отношений, которые не были распространены до этого [3, 4]. Например, в современной молодой семье оба супруга/родителя работают, в связи с этим распределение домашних обязанностей происходит между супругами поровну [5]. Сегодня многие молодые люди считают семью ценностью инструментального порядка, проще относятся к такой форме семейных отношений, как сожительство без официально зарегистрированного в органах ЗАГС брака, при создании семьи считают более приемлемой двухдетную или однодетную модель, также молодежь как норму семейных отношений рассматривает и модель семьи без детей $[6,7]$.

Происходящие в обществе трансформации учитываются и отражаются в рамках государственной семейной политики России, содержание которой направлено на развитие и поддержку молодой семьи, в свою очередь рассматриваемой государством в качестве одного из индикаторов развития российского социума [8].

В связи с тем, что семейная политика России направлена на укрепление семьи и семейных ценностей, она включает в себя различные механизмы реализации предусмотренных направлений, одним из которых являются государственные программы. На наш взгляд, очень актуально и значимо обратиться к рассмотрению реализации программ государственной поддержки российских молодых семей в рамках конкретного региона (в данной работе мы рассматриваем опыт Ростовской области).

Теоретико-методологическая база исследования. Проблемы, происходящие в сфере семейно-брачных отношений, в работах отечественных ученых представлены достаточно широким кругом исследований и научных тенденций. В рамках данных направлений исследований ученые обращаются к таким вопросам, как мотивы заключения брака и создания семьи [7], социальные роли супругов в молодой семье $[1,4,5]$, жизненный мир молодой семьи [9], репродуктивные установки и демографическое поведение молодых супругов $[10,11]$.

Анализ научной литературы, посвященной выбранному нами полю исследования, свидетельствует о том, что современные ученые считают проблемы молодой семьи важными, актуальными, научно и социально значимыми. Несмотря на многоплановость научно-исследовательских интересов современных фамилистов, обращение к государственной семейной политике в России остается одной из актуальных тем для исследователей.

Для решения цели, которая поставлена в данном исследовании, мы обращаемся к концепции социологии жизни, разработан- 
ной Ж. Т. Тощенко [12], и теории институализации молодой семьи Т.К. Ростовской [13].

Методологической базой данной работы стал анализ нормативно-правовых документов Российской Федерации, связанных с семейной политикой России: Концепция государственной семейной политики в Российской Федерации на период до 2025 года, региональные нормативные документы семейной политики в Ростовской области, а также данные, представленные на официальном сайте Министерства труда и социальной политики Ростовской области.

Молодая семья как объект государственной семейной политики. При исследовании семьи отечественные ученые опираются на два основных подхода: кризисный $[14]$ и эволюционный $[15,16]$. Для многих исследователей вопрос об ослаблении или трансформации института семьи остается дискуссионным.

Анализ научной литературы по проблемам семьи показывает, что также нет единого мнения среди исследователей по определению дефиниции «молодая семья». Поскольку в рамках данной работы мы проводим анализ государственных программ поддержки молодой семьи федерального и регионального уровня, то мы используем определения молодой семьи, данные в нормативно-правовых документах РФ.

В Основах государственной молодежной политики в Российской Федерации на период до 2025 год указано, что «молодая семья семья, состоящая в первом зарегистрированном браке, в которой возраст каждого из супругов либо одного родителя в неполной семье не превышает 30 лет (для участников жилищных программ поддержки молодых семей возраст участников увеличивается до 35 лет)» [17]. В Федеральном законе, который был принят 30 декабря 2020 г., «О молодежной политике в Российской Федерации» под молодой семьей подразумеваются «лица, состоящие в заключенном в установленном законодательством Российской Федерации порядке браке, в том числе воспитывающие ребенка (детей), либо лицо, являющееся единственным родителем (усыновителем) ребенка (детей), в возрасте до 35 лет включительно» [18]. Таким образом, мы видим, что характеристики молодой семьи трансформировались: не указывается очередность заключения брака, и возраст молодых супругов увеличивается до 35 лет.

Рассмотренная нами научно-исследовательская литература, данные Федеральной службы государственной статистики и эмпиричных исследований позволили определить проблемы, которые беспокоят российские семьи, в том числе и молодых супругов.

Опираясь на исследование «Жизненный мир молодой семьи в Ростовской области», отметим, что одними из распространенных проблем для семьи, по мнению молодых супругов, являются: жилищные трудности, материальные проблемы, проблемы с трудоустройством, утрата семейных ценностей, ухудшение состояния здоровья супругов, нарушение воспитательной и досуговой функции семьи [19].

Многие из перечисленных проблем молодые семьи не в состоянии решить без помощи и поддержки государственных органов. В связи с этим в Российской Федерации существует государственная семейная политика.

В нашей стране термин «семейная политика» появился в 70-е годы XX века. В 2014 году в России была принята Концепция государственной семейной политики до 2025 года, стратегическими задачами которой является поддержка, укрепление и защита семьи и ценностей семейной жизни, создание необходимых условий для выполнения семьей ее функций, повышение качества жизни семей [8]. Для достижения перечисленных задач определены механизмы поддержки молодых семей: получение женщинами ежемесячного пособия по уходу за ребенком, увеличение денежного пособия по беременности и родам и ежемесячного пособия по уходу за ребенком работающим женщинам, получение родового сертификата и материнского капитала, строительство перинатальных центров. В связи с трудной эпидемиологической обстановкой, которая возникла в 2020 году из-за распространения новой коронавирусной инфекции и повлияла на экономическую стабильность многих российских семей, особенно молодых, имеющих детей, государство установило новые льготы и поддержку для некоторых категорий граждан. Сюда следует отнести выплаты, которые 
предоставило государство на детей до 3 лет, единовременную выплату на детей от 3 до 16 лет, а также ежемесячную выплату на детей в возрасте от 3 до 7 лет.

На наш взгляд, особой актуальностью пользуется формирование концепции социального партнерства между семьей, органами власти, общественными объединениями и некоммерческими организациями.

Программы поддержки молодой семьи в Ростовской области. Обозначенные в рамках упомянутой нами Концепции государственной семейной политики в Российской Федерации на период до 2025 г. задачи [8] смогут быть успешно реализованы на уровне регионов за счет слаженной работы государственных органов, общественных объединений НКО и самих семей.

На наш взгляд, одним из механизмов успешной деятельности государственных органов в рамках семейной политики является реализация федеральных и региональных программ поддержки молодой семьи.

На территории Ростовской области для поддержки и развития молодых семей региона реализуется Федеральная целевая программа «Жилище» на 2015-2020 годы и государственная программа Ростовской области «Обеспечение доступным и комфортным жильем населения Ростовской области». По информации, которая опубликована на официальном сайте Правительства Ростовской области, с помощью работы данных программ в ближайшие три года жилищные условия за счет социальных выплат улучшат 553 молодые семьи региона.

Помимо жилищной проблемы, молодые семьи волнуют проблемы ухудшения здоровья и репродуктивной функции, что находит отражение в мероприятиях Федеральной целевой программы «Здоровье». Например, в Ростове-на-Дону благодаря реализации этой ФЦП 10 лет назад открылся Областной перинатальный центр. В настоящее время государство уделяет огромное внимание репродуктивному здоровью молодых супругов, в связи с чем по программам ОМС проводится ЭКО. Например, в 2020 году в регионе было проведено более 1000 ЭКО.

Касаясь демографической политики исследуемого региона, отметим, что она реа- лизуется на основе Концепции демографической политики Ростовской области на период до 2025 года [20]. По предварительным данным Ростовстата, в 2020 году родилось 36,5 тыс. детей, показатель смертности населения 64,2 тыс. человек за год обусловил естественную убыль населения - 27,7 тыс. человек. В Ростовской области Министерство труда и социального развития является ответственным за реализацию регионального проекта «Финансовая поддержка семей при рождении детей (Ростовская область)». В рамках реализации данного проекта в 2020 году в Ростовской области 28,4 тыс. семей получили выплату в связи с рождением (усыновлением) первого ребенка, также 3,9 тыс. семей использовали региональный материнский капитал. В настоящее время размер регионального материнского капитала в Ростовской области составляет 125775 руб. Также стоит отметить тот факт, что государственные органы региона большое внимание уделяют информированию населения о мерах социальной поддержки семей. Например, в 2020 году региональными органами власти было подготовлено 2834 публикации по этой теме.

Заключение. На основе проанализированных нами научных источников, нормативно-правовых документов федерального и регионального уровней, связанных с реализацией государственной семейной и демографической политики, мы выделили основные направления семейной политики в области поддержки молодой семьи: повышение ценности семьи, экономическая поддержка семей, помощь в улучшении жилищных условий, поддержка репродуктивной функции семьи.

Реализация перечисленных нами в рамках данного исследования программ не ограничивается выплатами социальных субсидий и предоставлением различных льгот и пособий. Спектр мер, направленных на реализацию Концепции, состоит из мероприятий, которые организовывает Правительство Ростовской области, Министерство труда и социальной защиты Ростовской области, общественные организации, центры социального обслуживания населения, некоммерческие организации. 
Таким образом, реализация государственной семейной политики в России и исследуемом регионе представляет собой многоаспектную деятельность, одним из механизмов работы которой являются государственные программы поддержки молодых семей. Ocновными задачами государственных программ является улучшение социально-экономического положения молодых семей региона и повышение уровня рождаемости как в Ростовской области, так и в стране в целом.

Рассмотренный нами опыт Ростовской области свидетельствует о том, что государственные программы поддержки молодых семей реализуются и пользуются популярностью среди молодых супругов. Отметим, что позитивный опыт не исключает и ряда негативных тенденций, которые касаются того, что получение поддержки в рамках данных программ - это выполнение установленных формальных требований, которым могут не соответствовать молодые семьи. Также к негативным тенденциям относится то, что не все волнующие молодых супругов проблемы могут быть решены в рамках обозначенных государственных программ поддержки.

\section{Литература}

1. Евграфова Ю.А. Ролевая структура в молодой супружеской паре [Электронный ресурс] // Вестник СПбГУ. Серия 16: Психология. Педагогика. - 2019. - №4. - Peжим доступа: https://cyberleninka.ru/article/n/ rolevaya-struktura-v-molodoy-supruzheskoypare (Дата обращения: 18.03.2021).

2. Якупова Г.А. Трансформация функций сельской молодой семьи в современных условиях // Экономические и гуманитарные науки. - 2017. - №2 (301). - С. 23-34.

3. Любавина Н.В., Белова Ю.А. Семейные традиции в условиях трансформации института семьи: сравнительный анализ мнений старшего и молодого поколений [Электронный ресурс] // Хуманитарни Балкански изследвания. - 2020. — №3 (9). - Режим доступа: https:/cyberleninka.ru/article/n/ semeynye-traditsii-v-usloviyah-transformatsiiinstituta-semi-sravnitelnyy-analiz-mneniystarshego-i-molodogo-pokoleniy (Дата обращения: 18.03.2021).
4. Рождественская Е. Ю. Вовлеченное отцовство, заботливая маскулинность // Мониторинг. - 2020. — №5 (159).

5. Кабайкина О.В. Трансформация роли женщины в современном обществе: в семье и на работе // Социология. - 2016. — №4. C. $163-169$.

6. Ростовская T.К., Кучмаева О.В. Семья и семейные ценности в современном мире / Российская молодежь: социально-демографический портрет и система ценностей в контексте многонациональной основы Российского государства: монография. - М.: Перспектива, - 2017. - С. 303-315.

7. Ростовская Т.К., Кучмаева О.В. Трансформация образа желаемой модели семьи у разных поколений: результаты Всероссийского социологического исследования [Электронный ресурс] // Вестник РУДН. Серия: Социология. — 2020. — №3. - Peжим доступа: https:/cyberleninka.ru/article/n/ transformatsiya-obraza-zhelaemoy-modeli-semiu-raznyh-pokoleniy-rezultaty-vserossiyskogosotsiologicheskogo-issledovaniya (Дата обращения: 20.03.2021).

8. Распоряжение от 25 августа 2014 года №1618-p. Концепция государственной семейной политики в Российской Федерации на период до 2025 года [Электронный ресурс]. - Режим доступа: https:// rg.ru/2014/08/29/semya-site-dok.html (Дата обращения: 20.03.2021).

9. Артамонова Я.В., Барсуков С. С. Конструирование жизненного мира молодой семьи в условиях изменяющейся реальности [Электронный ресурс] // Государственное и муниципальное управление. Ученые записки. - 2020. - №4. - Режим доступа: https:// cyberleninka.ru/article/n/konstruirovaniezhiznennogo-mira-molodoy-semi-v-usloviyahizmenyayuscheysya-realnosti (Дата обращения: 20.03.2021).

10. Гудкова Т.Б. Репродуктивные намерения россиян: мотивация и сдерживающие факторы [Электронный ресурс] // Демографическое обозрение. - 2019. — №4. Режим доступа: https://cyberleninka.ru/ article/n/reproduktivnye-namereniya-rossiyanmotivatsiya-i-sderzhivayuschie-faktory (Дата обращения: 20.03.2021).

11. Верещагина А.В., Кротов Д.В., Самыгин С.И. Трансформация семейно-брач- 
ных ценностей молодежи на Юге России: архаизация, традиционализация, модернизация? // Гуманитарные, социально-экономические и общественные науки. - 2020. №2. - С. 31-35.

12. Социология жизни: монография/ Ж.Т. Тощенко. - М.: ЮНИТИ-ДАНА, 2016. - $399 \mathrm{c}$.

13. Ростовская T.К. Молодая семья в современном российском обществе: монография / Т. К. Ростовская. - Иваново: Изд-во «Ивановский государственный университет», 2005. - $107 \mathrm{c}$.

14. Синельников А.Б. Трансформация типа семьи и проблема свободы личности // Социальная и демографическая политика. 2006. - №2. - С. 18-29.

15. Вишневский А.Г. После демографического перехода: дивергенция, конвергенция или разнообразие? // Общественные науки и современность. - 2015. - №2. C. $112-129$.

16. Гидденс Э. Трансформация интимности: сексуальность, любовь и эротизм в современных обществах. - СПб, 2004. $208 \mathrm{c}$.

17. «Основы государственной молодежной политики в Российской Федерации на период до 2025 год» [Электронный ресурс]. Режим доступа: http:/government.ru/media/ files/ceFXleNUqOU.pdf (Дата обращения: 20.03.2021).

18. Федеральный закон от 30 декабря 2020 г. №489-Ф3 «О молодежной политике в Российской Федерации» [Электронный ресурс]. — Режим доступа: https://www.garant. ru/products/ipo/prime/doc/400056192/ (Дата обращения: 20.03.2021).

19. Сердюченко Я.В. Жизненный мир молодой семьи: особенности формирования и риски разрушения (на материалах Ростовской области): автореф. дис. ... на соиск. уч. ст. канд. соц. наук. Южный федеральный университет. - Ростов-н/Д., 2018. - 38 c.

20. Постановление Администрации Ростовской области от 16.12.2009 г. №672 «Концепция демографической политики Ростовской области на период до 2025 года» [Электронный ресурс]. - Режим доступа: https:// www.donland.ru/activity/1182/ (Дата обращения: 20.03.2021).

\section{References}

1. Evgrafova Ju. A. Rolevaja struktura v molodoj supruzheskoj pare [Role structure in a young married couple] [Jelektronnyj resurs] // Vestnik SPbGU. Serija 16: Psihologija. Pedagogika [Bulletin of St. Petersburg State University. Series 16: Psychology. Pedagogy]. 2019. — №4. - URL: https://cyberleninka. $\mathrm{ru} /$ article/n/rolevaya-struktura-v-molodoy-supruzheskoy-pare (Date accessed: 18.03.2021).

2. Jakupova G.A. Transformacija funkcij sel'skoj molodoj sem'i v sovremennyh uslovijah [Transformation of the functions of a rural young family in modern conditions] // Jekonomicheskie i gumanitarnye nauki [Economic and humanitarian sciences]. - 2017. №2 (301). - Pp. 23-34.

3. Ljubavina N.V., Belova Ju. A. Semejnye tradicii $v$ uslovijah transformacii instituta sem'i: sravnitel'nyj analiz mnenij starshego i molodogo pokolenij [Family traditions in the conditions of transformation of the family institute: a comparative analysis of the opinions of older and younger generations] [Jelektronnyj resurs] // Humanitarni Balkanski izsledvanija. — 2020. — №3 (9). — URL: https://cyberleninka.ru/article/n/semeynye-traditsii-v-usloviyah-transformatsii-instituta-semi-sravnitelnyyanaliz-mneniy-starshego-i-molodogo-pokoleniy (Date accessed: 18.03.2021).

4. Rozhdestvenskaja E. Ju. Vovlechennoe otcovstvo, zabotlivaja maskulinnost' [Involved fatherhood, caring masculinity] // Monitoring. - 2020. - №5 (159).

5. Kabajkina O.V. Transformacija roli zhenshhiny v sovremennom obshhestve: v sem'e i na rabote [Transformation of the role of women in modern society: in the family and at work] // Sociologija. - 2016. - №4. - Pp. 163-169.

6. Rostovskaja T.K., Kuchmaeva O.V. Sem'ja i semejnye cennosti v sovremennom mire [Family and family values in the modern world] / Rossijskaja molodezh': social'no-demograficheskij portret i sistema cennostej v kontekste mnogonacional'noj osnovy Rossijskogo gosudarstva: monografija [Russian youth: socio-demographic portrait and system of values in the context of the multinational basis of the Russian state: monograph]. - Moscow: Perspektiva, - 2017. - Pp. 303-315.

7. Rostovskaja T.K., Kuchmaeva O.V. Transformacija obraza zhelaemoj modeli sem'iu raznyh 
pokolenij: rezul'taty Vserossijskogo sociologicheskogo issledovanija [Transformation of the image of the desired family model in different generations: the results of the All-Russian sociological study] [Jelektronnyj resurs] // Vestnik RUDN. Serija: Sociologija [Bulletin of the RUDN. Series: Sociology]. — 2020. — №3. - URL: https:// cyberleninka.ru/article/n/transformatsiya-obrazazhelaemoy-modeli-semi-u-raznyh-pokoleniy-rezultaty-vserossiyskogo-sotsiologicheskogo-issledovaniya (Date accessed: 20.03.2021).

8. Rasporjazhenie ot 25 avgusta 2014 goda №1618-r. Koncepcija gosudarstvennoj semejnoj politiki v Rossijskoj Federacii na period do 2025 goda [Order №1618-r of August 25, 2014. The concept of State family policy in the Russian Federation for the period up to 2025] [Jelektronnyj resurs]. — URL: https://rg.ru/2014/08/29/semya-site-dok.html (Date accessed: 20.03.2021).

9. Artamonova Ja. V., Barsukov S.S. Konstruirovanie zhiznennogo mira molodoj sem'i v uslovijah izmenjajushhejsja real'nosti [Construction of the life world of a young family in the conditions of changing reality] [Jelektronnyj resurs] // Gosudarstvennoe i municipal'noe upravlenie. Uchenye zapiski [State and municipal management. Scientific notes]. - 2020. — №4. - URL: https:// cyberleninka.ru/article/n/konstruirovanie-zhiznennogo-mira-molodoy-semi-v-usloviyah-izmenyayuscheysya-realnosti (Date accessed: 20.03.2021).

10. Gudkova T.B. Reproduktivnye namerenija rossijan: motivacija i sderzhivajushie faktory [Reproductive intentions of Russians: motivation and deterrent factors] [Jelektronnyj resurs] // Demograficheskoe obozrenie [Demographic review]. - 2019. — №4. — URL: https://cyberleninka.ru/article/n/reproduktivnyenamereniya-rossiyan-motivatsiya-i-sderzhivayuschie-faktory (Date accessed: 20.03.2021).

11. Vereshhagina A. V., Krotov D. V., Samygin S.I. Transformacija semejno-brachnyh cennostej molodezhi na Juge Rossii: arhaizacija, tradicionalizacija, modernizacija? [Transformation of family and marriage values of youth in the South of Russia: archaization, traditionalization, modernization?] // Gumanitarnye, social'no-jekonomicheskie i obshhestvennye nauki [Humanities, socio-economic and social sciences]. - 2020. — №2. - Pp. 31-35.

12. Sociologija zhizni: monografija [Sociology of life: a monograph] / Zh. T. Toshhenko. Moscow: JuNITI-DANA, 2016. — 399 p.
13. Rostovskaja T.K. Molodaja sem'ja v sovremennom rossijskom obshhestve: monografija [Young family in modern Russian society: monograph] / T.K. Rostovskaja. - Ivanovo: Izd-vo «Ivanovskij gosudarstvennyj universitet», 2005. - $107 \mathrm{p}$.

14. Sinel'nikov A.B. Transformacija tipa sem'i i problema svobody lichnosti [Transformation of the family type and the problem of personal freedom] // Social'naja i demograficheskaja politika [Social and demographic policy]. 2006. - №2. - Pp. 18-29.

15. Vishnevskij A. G. Posle demograficheskogo perehoda: divergencija, konvergencija ili raznoobrazie? [After the demographic transition: divergence, convergence or diversity?] // Obshhestvennye nauki i sovremennost' [Social Sciences and Modernity]. — 2015. — №2. Pp. 112-129.

16. Giddens Je. Transformacija intimnosti: seksual'nost', ljubov' i jerotizm v sovremennyh obshhestvah [Transformation of intimacy: sexuality, love and eroticism in modern societies]. Saint Petersburg, 2004. - 208 p.

17. «Osnovy gosudarstvennoj molodezhnoj politiki v Rossijskoj Federacii na period do 2025 god» [«Fundamentals of the state youth policy in the Russian Federation for the period up to 2025»] [Jelektronnyj resurs]. — URL: http:// government.ru/media/files/ceFXleNUqOU.pdf (Date accessed: 20.03.2021).

18. Federal'nyj zakon ot 30 dekabrja 2020 g. №489-FZ «O molodezhnoj politike v Rossijskoj Federacii»» [Federal Law №489-FZ of December 30, 2020 «On Youth Policy in the Russian Federation»] [Jelektronnyj resurs]. URL: https://www.garant.ru/products/ipo/ prime/doc/400056192/ (Date accessed: 20.03.2021).

19. Serdjuchenko Ja. V. Zhiznennyj mir molodoj sem'i: osobennosti formirovanija i riski razrushenija (na materialah Rostovskoj oblasti): avtoref. dis. ... na soisk. uch. st. kand. soc. nauk. Juzhnyj federal'nyj universitet [The life world of a young family: features of formation and risks of destruction (on the materials of the Rostov region): Ph. D. (Sociology) Thesis. Southern Federal University]. - Rostov-onDon, 2018. $-38 \mathrm{p}$.

20. Postanovlenie Administracii Rostovskoj oblasti ot 16.12.2009 g. №672 «Koncepcija demograficheskoj politiki Rostovskoj oblasti na pe- 
riod do 2025 goda» [Resolution of the Administration of the Rostov region of 16.12.2009 №672 «The concept of demographic policy of the Ros- tov region for the period up to 2025»] [Jelektronnyj resurs]. — URL: https://www.donland.ru/activity/1182/ (Date accessed: 20.03.2021).

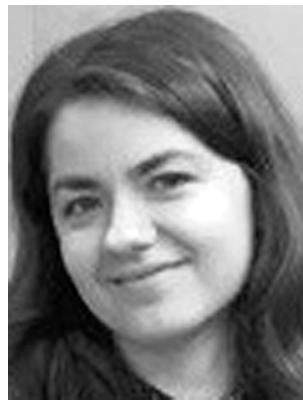

Артамонова Яна Викторовна - кандидат социологических наук, старший преподаватель кафедры региональной социологии и моделирования социальных процессов Института социологии и регионоведения Южного федерального университета. Сфера научных интересов: семья, семейно-брачные отношения, молодая семья, молодежь. Стаж научной работы - 3 года.

Artamonova Yana Viktorovna - Candidate of Sociological Sciences, Senior Lecturer of the Department of Regional Sociology and Modeling of Social Processes, Institute of Sociology and Regional Studies, Southern Federal University. Research interests: family, family-marriage relations, young family, youth. The experience of scientific work is 3 years.

344006, г. Ростов-на-Дону, ул. Пушкинская, 160 160 Pushkinskaya st., 344006, Rostov-on-Don, Russia E-mail: janaserduchenko@mail.ru

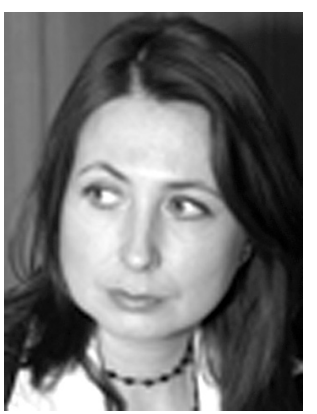

Липчанская Ирина Владимировна - кандидат философских наук, доцент кафедры философии и культурологии Ростовского государственного экономического университета (РИНХ). Сфера научных интересов: элитология, проблемы генезиса научной элиты, исследования в сфере философии и методологии науки. Стаж научной работы - 18 лет.

Lipchanskaya Irina Vladimirovna - Candidate of Philological Sciences, Associate Professor of Philosophy and Cultural Studies of Rostov State University of Economics (RSUE). Research interests: elitology, the genesis of the scientific elite, research in the field of philosophy and methodology of science. Experience of scientific work - 18 years.

344002, г. Ростов-на-Дону, ул. Большая Садовая, 69 69 Bolshaya Sadovaya st., 344002, Rostov-on-Don, Russia E-mail: lipiv@list.ru. 